\title{
LA DEIXIS PERSONAL EN BENASQUÉS
}

\author{
JOSÉ ANTONIO SAURA RAMI \\ (Universidad de Zaragoza)
}

\begin{abstract}
The aim of my study is to present an overview of the basic units which constitute the foundation of deixis in this minority language from the Pyrenees-Aragon area. I assume the principle that deixis is bound to the grammatical persons, either directly (c.g. personal nouns) or indirectly, by means of reference to the third person, and always expresses the relationship between the object shown and the persons of the speech (e.g. demonstratives, adverbial demonstratives).
\end{abstract}

\section{Introducción}

Quierc versar este trabajo sobre las unidades fundamentales que sirven para establecer la deixis en esta variedad lingüística del Pirineo aragonés, pero siempre que cxista una vinculación con las personas gramaticales'. Ésta se puede realizar directamente — sustantivos personales- o indirectamente, al referirse a la tercera persona, pero indicando la relación mantenida por lo mostrado respecto de las personas del cnunciado -demostrativos, elementos adverbio-deícticos- (Alarcos, 1994: 91-92).

\section{Deixis directa: los sustantivos personales}

Las unidades que integran en benasqués el sistema de los sustantivos personales ${ }^{2}$ se recogen en el cuadro que presentamos a continuación:

\footnotetext{
'Hay que recordar, a este respecto, que los adverbios situacionales poseen también valores deícticos, pero de cllos no nos ocuparemos en este lugar.

${ }^{2}$ Adoptamos la terminología de Alarcos (1994: 71) para referimos a esta subespecie de los sustantivos que tienen la potestad de actuar de un modo autónomo en el enunciado, ya como unidad fónica ya como
} 


\begin{tabular}{|l|l|l|}
\hline & SINGULAR & PLURAL \\
\hline $\begin{array}{l}\text { PRIMERA } \\
\text { PERSONA }\end{array}$ & Yo & nusaltros, nusaltres / -as; naltres \\
\hline $\begin{array}{l}\text { SEGUNDA } \\
\text { PERSONA }\end{array}$ & tú & busaltros, busaltres / -as; baltres \\
\hline $\begin{array}{l}\text { TERCERA } \\
\text { PERSONA }\end{array}$ & ell, ella & ells, elles / ellas \\
\hline
\end{tabular}

Pasemos ahora a detallar pormenorizadamente tal sinopsis.

\subsection{Primera persona, singular}

\section{El significante correspondiente es yo $(<\mathrm{E}[\mathrm{G}] \mathrm{O})^{3}$ :}

No seré pas yo qui te dóne la ragón 'no seré precisamente yo quien te dé la razón' $(\mathrm{Rm} ., \mathrm{Gb} .)^{5}$.

Mira si yera yo chicot encara 'mira si era yo pequeño todavía' (Bq.).

unidad sintáctica, merced a su carácter tónico frente a los incrementos átonos, que pasan a depender de un verbo o un derivado verbal.

${ }^{3}$ Una forma similar (you) es también la del gascón de los valles de Aspe, Azun, Gave de Pau, Campan y Aure (Rohlfs, 1970: 181). Para la variante benasquesa nos inclinamos por el usual tratamiento interno de /e/ breve tónica en inicial absoluta (cf. Saura, 1997: 316-317) con ulterior reducción del triptongo, como parece haber sucedido en otros espacios (Menéndez Pidal, 1940: 250 y 57; Alvar-Pottier, 1983: 117 118; Lloyd, 1993: 311-314). En cuanto al catalán, io se atestigua desde los orígenes de la lengua y mantiene vigencia en todo el Centro y Mediodía del Principado de Cataluña, en Valencia, Ibiza y Formentera; en el dialecto occidental lo tenemos desde Tamarite de Litera, Azanuy, Calasanz, Lascuarre. Roda de Ribagorza hasta Piedrafita de Fadas, así como en los Valles de Bohí y Áneu (DECat., s.v.jo).

${ }^{4}$ De todos modos, lo usual en todos estos sustantivos es que, si no se les concede un valor marcadamente enfático o pleonástico (como aquí), no aparezcan, al ser suficiente la referencia de persona ya incluida en las lormas verbales; ahora bien, en el presente de subjuntivo, los imperfectos y el condicional del benasqués del sur del Valle (minche, minchaba, minchase, mincharía) la confusión eventual entre la primera y tercera personas del singular puede llegar a hacer necesario su uso.

${ }^{5}$ Damos aquí las equivalencias de las abreviaturas - agrupadas por zonas diatópicas $\mathbf{A}, \mathbf{B}$, $\mathbf{C}$, en las cuales se producen las variaciones lingüísticas- que irán surgiendo en lo sucesivo entre paréntesis y que corresponden a las localidades del Valle de Benasque donde se han recogido los textos en cuestión (he aquí también entre corchetes rectangulares los nombres autóctonos en el caso de que varíen respecto de los oficiales castellanos): An. = Anciles [Ansils], Bq. = Benasque [Benás], Cr. = Cerler [Sarllé], Er. = Eriste [Grist], Sh. = Sahún [Saúnc] (zona A); Ar. = Arasán, Bi. = Bisaurri [Bisa (g)urri], C.S. = Castejón de Sos [Castilló], Ch. = Chía, E.R. = El Run [El Ru], Es. = Eresué [Erisué], Gb. = Gabás, Li. = Liri [Llire], Re. = Renanué, Rm. $=$ Ramastué, So. $=$ Sos, Ss. $=$ Sesué, Ur. = Urmella, Vi. = Villanova [Vilanova] $($ zona B); Bu. = Buyelgas, Do. = Dos, L.M. = La Muria, S.F. = San Feliu, S.M. = San Martín [Samartí, Ve. = Veri [Verí] (zona C). 
Como es general en los dialectos aragoneses actuales ${ }^{6}$, el benasqués hace extensiva a esta primera persona la neutralización de la oposición morfológica entre las formas en función de sujeto y aquellas empleadas con término de preposición:

Que me posase a yo una dosena de truitas 'que me pusiese a mí una docena de truchas' (Rm.).

¿Charrabets de yo? '¿hablabais de mí?' (Er., Sh.).

Igual hu podets lè sin yo 'lo podéis hacer igual sin mí' (Bq.).

[...] que la yo sería algún animal de istes de la selba encantats [...] ' $[\ldots]$ que para mí sería algún animal de estos de la selva encantados [...]' (Castán, 1991: 7).

[...] pero sólo arremeteba contra yo '[...] pero sólo arremetía contra mí' (Castán, 1991: 6).

En yo cònto que puets confià 'en mí creo que puedes confiar' (An.).

\subsection{Primera persona, plural}

Tenemos las formas (procedentes de una antigua aglutinación *nosaltros, -as $<$ NOS-ALTEROS, -AS) nusaltros ${ }^{7}$ para el masculino en las zonas A y B del Valle; nuscaltres para el femenino en A frente a nusaltras en $\mathrm{B}$, si bien estos femeninos se emplean poco en favor del masculino como término no marcado; $y$, finalmente, naltres $^{8}$ tanto para el masculino como para el femenino de la zona C. La

\footnotetext{
'Cf. Menéndez Pidal (1940: 250). En concreto, esta misma estructura reaparece en el ansotano (Alvar, 1978: 22), panticuto (Nagore, 1986: 68-69), belsetán (Badía, 1950: 105), chistavino (Mott, 1989: 64) o bajorribagorzano (Arnal, 1998: 290-291), y — limitada a la segunda persona-en el cheso (Bayo, 1978: 76): también en el gascón (v. gr. el aranés), frente al propio occitano antiguo y al catalán común (Corominas, 1991: 79; Rohlss, 1970: 181), si bien el catalán dialectal del Pallars y de la Ribagorza admiten a io (DECat., s.v.).

${ }^{7}$ Esla isoglosa léxico-morfologica llega hasta Bielsa, donde tenemos identidad con el benasqués (Badía, 1950: 105; Alvar, 1953: 212) y, por supuesto, incluye el Valle de Gistaín en el que Mott (1989: 65) documenta musatros, - as para la primera persona y vusatros / gusatros, -as (con equivalencia acústica = g) para la segunda; estas formas chistavinas, reiteradas en Graus (Alvar, 1954: 19), creemos que son cl resultado de una reducción del grupo alt- < ALT-, dado que en el benasqués también aparecen con carácter esporádico nusatros, atros, etc. (Sh.) y, además, el hecho se reitera en otras localidades de la Franja oriental como La Puebla de Roda, Arén y Tolva (ALEANR, XII, mapa 1607). Una panorámica de las diversas posibilidades fonéticas de este pronombre personal se ofrece en Badía (1981: 291-292).

En cuanto a las razones de su aglutinación histórica, cf. Alvar-Pottier (1987: 122-123).

${ }^{8}$ Es la misma documentada en las hablas más orientales de Aragón, la que hemos constatado en la localidad de Espés, y que Haensch (1959: 134) recoge, además, en Bonansa y Castanesa; para otras variantes catalano-occidentales yá plenas o reducidas (bisilábicas), cf. DECat., s.v. nós; una consideración más general de este fenómeno sobre una pespectiva peninsular puede verse en Frago (1978: 186).
} 
construcción es en este caso idéntica a la del singular, de modo que aparece en calidad de sujeto:

Nusaltros benim de sanc mol fòrta 'nosotros venimos de sangre muy fuerte' (Er.).

Al canto del barranco tenibam nusaltros un prau [...] 'al lado del barranco teníamos un prado' (Castán, 1991: 14).

O cn las distintos complementos preposicionales:

Bienc dan nusaltres que berem la boda 'ven con nosotras a ver la boda' (An., Bq.). Ragone de nusaltros 'habla de nosotros' (Er., Sh., Cr.).

Ta naltres sempre ha teniu algo espesial "para nosotros siempre ha tenido algo especial' (S.F.).

\subsection{Segunda persona, singular}

En estricto paralelismo con la primera persona" el nominativo tú $(<\mathrm{TU})$, además de sujeto:

Cuan yo correba per les montañes, tí encara yeres al cul del ou 'cuando yo corría por las montañas, tú aún eras pura posibilidad' (Er.).

Tí sí que en bas està de dolén de chico 'tú sí que fuiste travieso de pequeño' (Rm.). ¿Y tú desde agón m’has bisto? '¿y tú desde dónde me has visto' (Er.),

queda habilitado igualmente para el término de preposición:

Astò hu be portà ta tú 'esto lo traje para ti' (Bq.).

Dan lú encara se poríe puyà a Llardana 'contigo todavía se podría subir a Llardana' (Er.).

¡O, que per uí tot se aría perdeu! '¡es que por ti todo se habría perdido!' (Es.).

Contra tú las teniba, contra tú 'contra ti las tenía, contra ti' (Rm.).

Han tratau de tí 'han tratado de ti' (An., Gb.).

Como lórmula de tratamiento se emplean usté para el singular y ustedes para el plural, aunque su funcionamiento está en la órbita de la tercera persona (usté hu farà milló 'usted lo hará mejor').

\footnotetext{
"Vid. para cste punto en aragonés antiguo Menéndez Pidal (1940: 250), Umphrey (1911: 186), Cooper (1960: 227) y Frago (1977: 324).
} 


\subsection{Segunda persona, plural}

Para este supuesto se reproducen las mismas circunstancias que rigen en la primera persona de plural, de manera que se registran (procedentes de *bosaltros, $a s<$ VOS-ALTEROS, -AS) busaltros para el masculino en las zonas A y B; busaltres para el femenino en A frente a busaltras en B (con idéntica parquedad de emplco que nusaltres, -as); asimismo aparece baltres, que se atestigua en $\mathrm{C}$ para el masculino y el femenino. La configuración es aquí idéntica a la de nusaltros, por lo que aparece como sujeto:

Busaltros sots de lo que se bene tapau 'vosotros sois de lo que se vende tapado' (Er.).

Busaltros puyarets dan nusaltres a Saúnc 'vosotros subiréis con nosotras a Sahún' (Bq., Sh., An.).

¡Ome! be, ¿y busaltros? ‘ ¡hombre! bien, ¿y vosotros?’ (Bq.).

O en los diversos complementos:

Sin busaltros no arían podeu cargà 'sin vosotros no habríamos podido cargar' (Er.).

Adebán de busaltras m'i colaré yo cuan siga de ragón 'ante vosotros me pondré cuando sea razonable' (Ar.).

Això tos ue daría ta busaltros, pero hu he d'amenisté 'esto os lo daría para vosotros, pero lo necesito' (Rm.).

M'acòrdo molto de busaltros 'me acuerdo mucho de vosotros' (Gb.).

\subsection{Tercera persona, singular}

Ell (< ILLE) es la única posibilidad para el masculino en todo el Valle y para cualquicr función ${ }^{10}$ :

$E / l$ cn un pañolet fardèro pián una muda [...] 'él con un hatillo atando una muda [...]'

(Castán, 1991: 12).

Digú hu aríc dito d'ell 'nadie lo habría dicho de él' (Bq.).

L'hu be bere a ell 'se lo vi a él' (Ur., Ch.).

Se m'entrefà qu'cls querríc a tots adichós d'ell 'intuyo que los querría a todos debajo de él' (Cr.).

Per ell preguntam 'por él preguntamos' (Gb.).

\footnotetext{
${ }^{10}$ No existe, consccuentemente, aquí -y tampoco en plural- una forma tónica específica para cuando se produce identidad entre las personas sujeto y término de preposición: se dibe ta ell / fa ella 'decía para sí'...
} 
En lo que atañe a la forma femenina ella (< ILLA), cabe significar las mismas apreciaciones reseñadas arriba:

¡Elia ye la entrepetida y no pas yo! '¡ella es la metomentodo y no yo!' (C.S.)

¿Quî? ¿ella? ‘¿quién? ¿ella?' (So., Es., Ss. Gb.).

D'ella no me'n fío brenca 'de ella no me fío ni un ápice' (Li.).

Fè-ue per ella si ques 'hazlo por ella si quieres' (Er.).

Sí, ta ella que hu quergo 'sí, para ella lo quiero' (irónico) (Cr.).

\subsection{Tercera persona, plural}

Los plurales son respectivamente ells $(<\mathrm{ILLOS})$ y elles [zona A] / ellas [B y C] $(<$ ILLAS):

Ells han dito que no 'ellos han dicho que no' (Er., Ch., Ve.).

Puyarán elles dan nusaltros 'subirán ellas con nosotros' (Bq.).

Per cnsima d'ellas que ba brincà 'por encima de ellas saltó' (Rm.).

\section{Deixis indirecta: los demostrativos y adverbio-deícticos}

\subsection{Los demostrativos \\ 3.1.1. Preliminar}

Como es de esperar, la nota lexemática diferencial de este paradigma reside en su valor identificador, lo que les asimila al artículo, y en su función deíctica (Alarcos, 1994: 89, 91-92). Por lo demás, manifiestan una triple referencialidad en conexión con las formas latinas HIC, ISTE e ILLE ${ }^{11}$.

Desde una perspectiva morfemática, los demostrativos poseen una variación genérica triple - masculino, femenino y neutro-, y numérica doble — singular y plural- Además, en tanto que adjetivos — salvo el neutro- concordarán con los sustantivos de que dependan.

En cuanto al benasqués, las series de los demostrativos quedan explicitadas en el cuadro que sigue:

\footnotetext{
"En un plano general, esta conservación tripersonal — con la sustitución del demostrativo latino HIC, HAEC, HOC- es común a todo el iberorromance (Lloyd, 1993: 261).
} 


\begin{tabular}{|l|l|l|l|l|}
\hline MASC. SG. & FEM. SG. & MASC. PL. & FEM. PL. & NEUTRO \\
\hline isto / iste & Ista & istos/ istes & istes / istas & asò \\
\hline ixo / ixe & ixa & ixos / ixes & ixes / ixas & això / astò \\
\hline aquell & aquella & aquells & aquelles / -as & allò \\
\hline aguell & aguella & aguells & aguellas & allò \\
\hline
\end{tabular}

\subsubsection{Demostrativos masculinos y femeninos}

\subsubsection{Demostrativos relacionados con la primera persona}

a) Las variantes del masculino isto e istos son exclusivas de la zona A del Valle, lirente al resto que usa iste e istes $^{12}$; por lo que respecta a la terminación $/ 0 /, / 0 s / \mathrm{de}$ la primera, que reaparece en las hablas orientales de Bonansa y Castanesa (Haensch, 1959: 131), podemos pensar - al menos teóricamente- en una etimología que parta del acusativo ISTU, aunque es probable que se deba más bien a un hecho analógico; en fin, la /e/ de la variante iste, puede ser una vocal de apoyo ${ }^{13}$ :

\footnotetext{
${ }^{12}$ Tales formas simples, herederas directas del demostrativo latino $-\mathrm{y}$, por tanto, sin la anteposición del deíctico ECCE, que genera las castellanas antiguas, catalanas y gasconas - se han documentado igualmente en el gascón de la Ala Bigorra: ésta craba, éste gouyát, V. de Azun (Rohlfs, 1970: 188), y son habituales en catalán antiguo (Jaime 1, Llull...) y dialectal, donde grosso modo este, esta perduran en el ámbito valenciano, en Mallorca y a lo largo de la franja occidental catalana hasta dialectos pirenaicos del Pallars o Andorra, los cuales las reducen a determinadas fórmulas fijas: est an, ast an (DECat., s.y. es1). Iste se atestigua, asimismo, en el habla de Calvera y Las Farrerías frente a Serraduy, en que se da este (Haensch, 1974: 309), e isto es también de Noales según el mapa 1602 del ALEANR [t. XII]. LJana la atención el timbre vocálico de la sílaba inicial que no es regular (debiera haber sido /e/ por proceder de una I breve latina como en aragonés - v. gr. este, estes en Gistaín [Mott, 1989: 64]--, catalán o castellano); es probable que ello sea debido a la influencia del demostrativo de segunda distancia $i x o / i x e$ en que este proceso sí resulta regular a partir de una reducción desde /eix/. Recordemos que monoptongaciones de este tenor son frecuentes en este espacio dialectal: benasqués ixà $<$ deixà $<$ LAXARE, belsetán lixiba $<$ leixiba $<$ LIXIVA, etc.

${ }^{13}$ Scría tentadoramente fácil propugnar que iste $\mathrm{y}$, obviamente, también ixe pudieran proceder de los nominativos latinos ISTE e IPSE (así parece asumirlo, por ejemplo, Rohlfs [1970: 188]), pero requisitos fonćticos al margen- no es muy lógico aceptar una posibilidad tal, dada la generalización del acusativo como caso único en latín vulgar (Alvar-Pottier, 1987: 106); ahora bien, también es seguro, por otra parte, que $\mathrm{a} / \mathrm{e} /$ benasquesa en nada se debe a la influencia de los modelos castellanos, porque con independencia de la presencia de esta terminación en valenciano (vid. DECat., s.v. est), reaparece tambićn en el gascón (cf. supra). Queda también claro que el benasqués es un sistema linguí́stico que mantiene generalmente la /o/ en el singular (Saura, 1997: 321), pero ya que en este tipo de contextos los plurales se realizan aquí mediante el morfo /os/: bidellàs / bidellìsos, cafís / cafísos, ficós / ficosos, camús / cammisos, ctc., quizá en la zona A estemos ante una /o/ secundaria procedente de los plurales masculinos (algo así como lo verificado en naso 'natiz' < nasos o plloso 'lloro' < pllosos), mientras que en las zonas B y C triunfó la adopción de una vocal de apoyo en el singular (una combinación *ist [sg.] e "ists [pl.] resultaba, en cualquier caso, muy compleja), sobre la que se modeló el plural. En nuestra
} 
Isto bar ye el milló de to’ lo llugà 'este bar es el mejor de todo el pueblo' (Bq.). Isto cuento me'l ba contà una llolla mol Ilolla [...] 'este cuento me lo contó una vieja muy vieja [...]' (Ballarín, 1972: 175).

¡Me'n fan de mal istos peus! ‘¡cómo me duelen los pies!' (Er.).

¿Qué cònte isto moset? ‘qué cuenta este chico?' (Sh.).

Istos tipos no'n saben got 'estos tipos no saben nada' (An.)

Frente a:

El ibèrt per iste país ye una purificasión ta tots "el invierno en este valle es una purificación para todos' (Castán, 1991: 10).

Iste animal d'ome 'este animal de hombre' (Gb.).

Per istes camíns no se puede pasà 'por estos caminos no se puede pasar' (Rm., Gb., Ur.).

¿T'agón apretas dan istes falandraixos? ¿ ¿para dónde te encaminas con estos harapos?' (Rm.).

b) El Cemenino singular ista (< ISTA) es uniforme en todo el territorio:

Ta ista siempre ba be 'para ésta siempre va bien' (Rm., Vi.).

O que ista ye de cuidau 'es que ésta es de cuidado' (An.).

¿Ista u l'altra ques? ¿quieres ésta o la otra? (Sh.).

¡Una oportunidat coma ista! '¡una oportunidat como ésta! (Bq.)'.

Ista sí que me l'ha apretau 'ésta sí que me la ha jugado' (Er.).

c) Y lógicamente en el plural incide la usual división geográfica sobre la base del cierre de /a/ átona final ante consonante: istes giielles (A) / istas giiellas (B, C) 'estas ovcjas'. Hay que resaltar que, en consecuencia, la forma istes equivale a 'éstas' cn A (istes pomes 'estas manzanas'), pero significa 'éstos' en el resto del Valle (istes omes 'estos hombres').

d) En otro orden de cosas, se constata la aglutinación del demostrativo en el sintagma ista nit 'esta noche' que pasa a ser istanit (Bq.), y estanit (Er.) ${ }^{14}$ : estanit pasada no n'he cllucau un gïello 'esta noche pasada no he pegado ojo' (Er.).

zona $\mathrm{A}$, isto se vio al margen de tales fenómenos probablemente porque allíla le/ como vocal de apoyo habría provocado homonimia entre el femenino y masculino de plural (vid. infra). Cuestión especialmente ardua, como se ve, y más habida cuenta de la ausencia de documentación antigua, aunque taì vez no resulte ocioso señalar que tanto la unidad aquell. como todo cil subsistema del neutro se hallan en la órbita del calalán.

${ }^{1.4}$ En la pura teoría, podría plantearse la cuestión de si aquí la /e/ es originaria o se inscribe en la dinámica fluctuante del vocalismo átono benasqués, pero seguramente se trata de esto último, dada la lejanía del acento en el sintagma aglutinado: ista nít $>$ istanít $>$ estanít. 


\section{I.2.2. Demostrativos relacionados con la segunda persona}

a) Debemos hacer aquí idénticas apreciaciones a las avanzadas en el apartado anterior, de manera que las variantes masculinas ixo e ixos (<IPSU, IPSOS ${ }^{15}$ ) son propias de $\Lambda$, lrente al resto del Valle, en que aparecen ixe e ixes:

Ixo mirc contra el gobierno 'ése es bizco' (proverbio).

Ixo ome ye malo del galillo 'ese hombre está enfermo de la garganta' (Bq.).

Dixa $i x o$ abrc, ixo altro ye milló 'deja ese árbol, ése otro es mejor' (Er.).

Per ixe carnús de dòna no dixaré de fè-ue 'por ese asco de mujer no dejaré de hacerlo' (Rm.).

fxe portiello me abría costau ara una quinsena de puns 'ese portillo me habría costado ahora una quincena de puntos' (Castán, 1991: 5).

b) El lémenino singular $i x a(<$ IPSA) es también único para todo el Valle:

Ixa gillina parese que fa la cachamona 'esa gallina parece alicaída' (Er.).

El tío Fclipe ba arribà $i x a$ misma nit cargau de paquets [...] 'el tío Felipe llegó esa misma noche cargado de paquetes [...]' (Castán, 1991: 16).

Si te pènses que no la he chafau prou $i x a$ montaña 'si crees que no la he pisado bastante esa montaña (Cr.).

Ixa llitarrada d'astí tantós se'Is n'arrosegue 'ese alud de ahí casi los arrastra' (Er., Bq.).

c) Y, evidentemente, para el plural opera la regla citada antes: ixes carrères (A) I ixas carrèras $(\mathrm{B}, \mathrm{C})$ 'esas calles'; del mismo modo, ixes es 'ésas' en el norte, frente al resto del benasqués, donde pasará a significar 'ésos'.

\subsubsection{Demostrativos relacionados con la tercera persona $(<E C C U I L L E)^{16}$}

\footnotetext{
${ }^{15}$ Al parcece a través de una clapa intermedia *ICSE que ya puso de manifiesto García de Diego (cf. Alvar, op. cit. $i l f r(a)$. Éste es un deíctico presente en textos aragoneses antiguos como el de Roncesvalles (eisos), en los cuales se documentan abundantes las formas exe, eixe, eixa o eixo; exe, exa, exo, por su parle, aparecen en Bolea y Loarre; además, estadios con reducción /ei/ > /i/ del diptongo inicial comunes en aragonés y en ciertos dialectos del catalán occidental (Valle de Bohí), pero también en lierras de Valencia (DECát, s.v. eix) - son los propios de Hecho, Ansó y Fanlo: ixe hombre, ixa casa, una ísoglosa que tendría su límite meridional en Benabarre e Ipiés, pero los vemos asimismo en ciertos valles gascones (Azun, Gave de Pau): icho medicho, icha bets, iches cás, ichos crabos (Alvar, 1953: 213, y 1978: 23; Bayo, 1978: 50; Rohlfs, 1970: 188). Finalmente, no nos consta una variante aguixo, tgıtixa que Haensch (1959: 131) ofrece para Bisaurri y Renanué, aunque sí existe en la localidad oriental de Noales (ALEANR, XII, mapa 1603).

${ }^{16}$ En cuanto a la pura etimología de esta unidad, autores como Y. Malkiel, «Between monogenesis and poligenesis», en Maher el cll., 1982, págs. 255-256, señalan la previa transformación en Dacia o Hispania de ECCE en *ACCU (cit. por Lloyd, 1993: 261).
} 
Las formas del masculino presentan una terminación en lateral palatal, frente a to que se documenta en los espacios dialectales típicamente aragoneses ${ }^{17}$. Por otro lado, los significantes con velar sonora /g/ son exclusivos la zona $\mathrm{C} ; \mathrm{y}$, si bien el mismo fenómeno sonorizador afecta al demostrativo de primera distancia en el catalán pallarés agét (Corominas, 1936: 265) y en el aranés aguest (Corominas, 1991: 94 y ss.), su explicación no puede converger, de modo que quizá se deba en benasqués a una asimilación a la sonora final ${ }^{18}$. Las restantes unidades no suponen variación respecto del castellano. He aquí ciertos ejemplos:

Aquell tèms ya se n'ha anau 'aquel tiempo ya se fue' (Cr.).

Pcr aquells crenchóns tienen la pasada els ixarsos "por aquellos riscos tienen su paso los rebecos' (Er.).

Dan bella moseta d'aquellas t'arías podeu casà tú 'con una de aquellas chicas te habrías podido casar tú' (Rm.).

Aquelles güelles son forastères 'aquellas ovejas son forasteras' (An.).

Aguellas oras que se n'anaban aprisa 'aquellas horas que se iban aprisa' (L.M.).

Hay que notar, por lo demás, la elisión que se verifica en el masculino ante cualquier vocal o $h$ muda; y en el femenino ante vocal /a/ en todos los demostrativos, cuando la dicción es rápida: ist'altro, ix'erco, ist'indio, ist'ome, ix'uso, aquell'áliga, ix'abella... Y la posibilidad de refuerzo mediante el indefinido altro < ALTERU: ixos altros, aquelles altres...

En relación con la posición en el sintagma nominal, los demostrativos prededen al núcleo (isto sep, ixa fienta), pero pueden ir detrás si interviene el artículo (el sep isto, la fienta ixa), lo que se produce con mucha frecuencia en benasqués, así como en otras zonas ribagorzanas (Arnal, 1998: 264).

\subsubsection{Demostrativos neutros}

Hay cuatro posibilidades en clara correlación con los ámbitos deícticos anteriores.

\footnotetext{
${ }^{17}$ El benasqués supone el límite de esta isoglosa, puesto que en el habla de Gistaín ya quedan atestiguadas las variantes aquel, aquela, aque(l)s, aquelas, y aquelo para el neutro (Mott, 1989:64 y 43) -con la pertinente reducción de - LL_, de acuerdo con la fonética local-; y en Bielsa interviene ol rotacismo que afecta tambièn al sustantivo personal: aquer, aquera, aqués, aqueras (Badia, 1950: 117). Pero el lénómeno de palatalización no es esporádico en el Valle de Benasque, antes bien al contrario muestra un evidente carácter sistemático: bell 'algún' < BELLU, estrell 'astro' < STRELLU, ell 'ć' < ILLE...

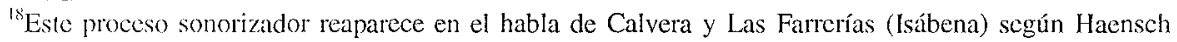
(1974:309).
} 
a) Asò 'esto' (<ECCE HÓC $\left.{ }^{19}\right)$ corresponde al campo mostrativo de isto / iste:

¿Qué scrà asò? '¿qué va a ser esto?' (Er.).

Asc̀ ye ta posà-hu a la llet 'esto es para ponerlo en la leche' (Bq.).

$[\ldots]$ y escribo asò ta que cuan me muera tots sepan quí yeba Sinforosa Sastre '[...] y escribo esto para que cuando muera todos sepan quién era Sinforosa Sastre' (Castán, 1991: 22).

Ye un caso asò 'es un caso esto' (Rm., Li.).

Assò no hu puesco entenre 'esto no lo puedo entender' (Cr.).

b) La deixis de això 'eso' (< IPSÚM ${ }^{20}$, por su parte, corre paralela al dominio de los demostrativos benasqueses ixo / ixe y es forma general hoy en benasqués:

Això ye cherà llum per les armaris 'eso es buscarle tres pies al gato' (expresión fija). Tanto bale això coma una tía a Fransa 'tanto vale eso como una tía en Francia' (proverbio).

No hu fa de buen sentí això 'no es agradable de oír eso' (Er., Rm.).

Això déu d'està mentira 'eso debe de ser mentira' (Ch.).

Se oye a menudo en la fórmula anafórica això rai 'eso es lo de menos'; también es notable su aplicación a determinadas personas con marcada intención despectiva: ¿quí ye això? '¿quién es ése [o ésa]?'.

c) Astò (<*ISTÚD ${ }^{21}$ ) coexiste con això como especifica acertadamente Ballarín (1978: 57), pero está muy limitado geográficamente, ya que tal empleo indistinto se circunscribe tan sólo a las localidades de Benasque y Cerler y, de modo más minoritario, a Eriste y Sahún:

Yo yera mol contén de podé chugà dan tot astò 'yo estaba muy contento de poder jugar con todo eso' (Ballarín, 1972: 175).

Per astò no i be binre 'por eso no vine' (Bq., Cr.).

\footnotetext{
${ }^{19}$ En realidad, tal demostrativo neutro es común al aragonés, donde se verifica ya en textos del s. XIII bajo las formas fo y zo; al catalán, en que aparece como açó (ço en posición proclítica), si bien con una mayor vitalidad en su ámbito occidental, Valencia e incluso Baleares; y, de la misma manera, a la lengua de Oc, para la que se documenta la voz aicsó (DECat., s.v. est; Alvar, 1953: 213).

${ }^{20}$ Este carícter agudo de això — como también de astò, allò, astí, alli, allà- han de deberse a un desplazamiento acentual de las bases latinas como señala el DECat., s.v. eix.

${ }^{21}$ Ya scñala Corominas (DECat., s.y. est), para quien astò es el resultado de una creación analógica tardía, que de todos los integrantes de tal sistema de deixis con referente neutro, éste es el de extensión más reducida en catalán, pues se limita a la zona entre Alcoy, Elche y Callosa, con idéntico valor al del benasqués (= això). En cualquier caso, astò no parece «una forma original de compromiso» (Plaza Boya, 1990: 166, nota 10) entre la catalana asò y la aragonesa isto, dado que resultaría muy difícil explicar cómo desde un punto de vista deíctico dos formas relacionadas con la primera distancia podrían haber generado otra nueva referida a la segunda distancia; y quizá haya contribuido en cierta medida para su consolidación en benasqués la analogía sobre el adverbio astí: asò = así, allò $=$ allí, astò $=$ astí.
} 
Astò yerà que bede-ue 'eso habrá que verlo' (Sh.).

Astò del turismo tot hu allere 'eso del turismo todo lo arrasa' (Er.).

d) Finalmente allò 'aquello' (< ILLÚD ${ }^{22}$ ) queda inscrito en una dinámica deíclica afín a aquell:

¡Allò sí que ba està una perdua gran! ‘¡aquello sí que fue una gran pérdida!' (Er., Rm.).

No me n'he acordau d'allò que me bas di 'no me he acordado de aquello que me dijiste' (Bq., An.).

Allò de cuan yes chobe, això ya hu he perdeu 'aquello de cuando eres joven, eso ya lo he perdido' (Vi.).

D'allò que te be ragonà no n'he sabeu res més 'de aquello de que te hablé no he sabido nada más' (Ss.).

También los neutros pueden verse reforzados por altro (cf. supra): asò / això / allò altro.

\subsection{Elementos adverbio-deícticos}

Dentro del apartadado semántico de los adverbios situacionales que indican referencias de carácter espacial, tenemos una serie de unidades que forman un subsistema estrechamente relacionado histórica y semánticamente con los demostrativos antes descritos.

\subsubsection{Las unidades 'asî', 'astî', 'allì' y 'allà'}

Posecn un campo mostrativo triple de acuerdo con aquéllos (y, por consiguiente, también con el sistema de los neutros benasqueses: asò, astò, allò, cf. $\$ 3.1 .3)$; y se hallan difundidos por todo el Valle.

a) Así < ECCE HIC. Es el adverbio de primera distancia ${ }^{23}$. Entra en combinación con otros adverbios: así baix(o) o así alto, para destacar la contraposición locativa (y asimismo, con determinadas preposiciones):

\footnotetext{
${ }^{22}$ Típico del catalán, su empleo ha sido ubicuo en todo el territorio desde el extremo norte de la Ribagorza y partc del Pallars hasta el valenciano meridional y las islas Baleares (DECat., s.v. ell).

${ }^{23}$ En riguroso paralelismo con el cat. $a c i$, occ. ant. aici, fr. $i c i$, it. ci; la forma catalana aparece ya en el s. $\mathrm{XI}$ y ha perdurado especialmente en Valencia, pero también en los Pirineos occidentales: Pallars, Noguera Ribagorzana c Isàbena (DECat., s.v. est). En benasqués no tenemos la forma aquî, ni con el significado castellano (lógicamente) ni con el catalán (= cast. ahí).
} 
Mos entenem mol be asi 'nos entendemos muy bien aquí' (Ar.).

Así baixo estem prou be, alto mos chelaban 'aquí abajo estamos bastante bien, arriba nos helábamos' (Er., Cr., Sh.).

Ta man d'así alto soleban binre apasián 'hacia aquí arriba solíamos venir paseando' (Rm., C.S., Ss., Vi.).

Baixa t'así a escalfà-te 'baja aquí para calentarte' (E.R.).

b) Astí < ISTÍC. Es el adverbio de segunda distancia ${ }^{24}$. Admite la misma combinatoria que el anterior:

Dixá astí la reducrta 'deja ahí la cuerda' (Bq., Rm.).

La ycrballoca - ya casi no se'n bei per astí- [...] 'el beleño - ya casi no se ve por ahí- [...]' (Castán, 1991:3).

Baixaban a Guayén per astí baix, per Aiguabat 'bajábamos a Guayente por ahí abajo, por Aiguabat' (Rm., Es.).

Apósta-t'ie astí que les tiraràs 'apóstate ahí que les dispararás' (Er.).

Para su adición a dellà, cf. infra $\$ 3.2 .2$.

c) Allí < ILLÍC y allà < ILLÁC. Son los adverbios de tercera distancia, y su funcionamiento es igual que el del catalán, de modo que el primero supone una relerencia locativa más concreta frente al segundo ${ }^{25}$.

|...] y allí se ba quedà hasta que se le'n ban llebà ta espellà-lo 'y allí se quedó hasta que sc lo llevaron para despellejarlo' (Castán, 1991: 5).

I donaben minchà en tèms alli 'ofrecían comida en tiempos allí' (Er.).

¿Si mos fotesan per allà? '¿y si nos metiéramos por allá?' (An., Bq.).

T'allà ta Fransa ban brincà, me pènso 'en dirección a Francia saltaron, creo' (Sh.).

Allà se combina con asígalto (con una velar sonora $/ \mathrm{g} /$ antihiática) para indicar Icjanía extraordinaria:

¿T'agón ye la cherada güe? — t'allà (a)sigalto 'para dónde te encaminas hoy? — para allá a lo lejos' (Er.).

Alà cisígalto les bem tinre que anà a buscà 'allá arriba tuvimos que ir a buscarlas' (Er.).

\footnotetext{
${ }^{24} \mathrm{Vigente}$ en Ribagorza y a lo largo de la frontera catalano-aragonesa hasta Fraga, pero igualmente presente con idéntica referencialidad por algunos valles altoaragoneses (Chistau), donde Corominas recoge por astí siempre baixa augual vid. en este sentido también Mott (1989: 97), aunque este autor le conficre el significado de 'aquí'. Pero se documenta ya en los Fueros de Aragón (s. XIII): non sía en testimonio recebido de astí avant y dar la mitad de todas las cosas partidas, sacadas d'astí las expensas (DECal., s.v. est).

${ }^{25}$ Para más precisioncs sobre el uso de ambos en catalán, véase DECat., s.v. ell.
} 
Como bien señala Arnal (1998: 398), bajo este epígrafe debemos consignar también al pronominalo-adverbial $i<$ IBI cuando se utiliza con su referencia locativa, aunque su deixis sea, por decirlo así, general (cf. Saura, 1998: 170-172).

\subsubsection{Las unidades 'ensà̀' y 'dallà'}

Por fin hay que reseñar dos unidades que manifiestan un nivel de operatividad casi nulo, ya que están prácticamente fosilizadas; su significado responde a la oposición (asimétrica, porque no tenemos las unidades deçà y enllà) centrípeto / centrífugo. La segunda puede verse matizada por la preposición part $<$ PARTE $^{26}$. Se trata de ensà 'hasta aquí' $<\mathrm{IN}+$ ECCE HAC y dellà 'más allá [de]' $<\mathrm{DE}+$ ILLAC $^{27}$. No se puede decir que ninguno de estos dos adverbios locativos posea siquiera una vitalidad mínima en benasqués y, si los mantenemos dentro de este punto, es más bien a título de curiosidad; efectivamente el primero de ellos sólo se utiliza en la expresión de / desde la ora ensà (y mái), que se pronuncia con retrotracción acentual en todo el Valle (la orán'nsa):

¡De la ora'nsa que fa que se n'ha anau! 'iel tiempo que ha pasado desde que se ha ido!' (Bq.).

¡Descle la ora'nsa y mái! ‘¡desde aquel entonces!' (Er., Rm.).

Por su parte dallà (= cat. dellà) se usa en la frase part dallà con la que los habitantes del Valle nos referimos a las gentes que viven en los valles del Noguera Ribagorzana y del Isábena.

Ixa dòna ye de part dallà 'esa mujer es del otro lado' (Er., Sh., Rm., C.S.).

Les Paúls ya ye part dallà 'Las Paúles forma parte de la otra vertiente' (Bq., An., Cr.).

\footnotetext{
${ }^{2 n}$ La onomástica nos lo manifiesta en el microtopónimo Parllaigua (Er.) < PARTE ILLA AQUA 'el prado que se halla al otro lado del río' (desde la perspectiva del pueblo de Eriste). El topónimo se recoge ambién en la localidad de Las Paúles, al este del Valle de Benasque (DECat. s.v. part). Por otro lado, lit especialización de la voz caigua como río o afluente de río es relativamente frecuente en benasqués (L'Aigua Mayò 'el río Ésera' [Bq.], L'Aigüeta de la Ball 'El Barranco de La Vall' [Er., Sh.].

${ }^{27}$ Es propiamente en los dominios lingüísticos del catalán (ençà / enllà, deçà / dellà) y del gascón (ensà / enlà, dessà / delà) donde estos adverbios configuran un subsistema vivo de oposición, absolutamente residual e incompleto en nuestro dialecto como se ve, porque éste prefiere el auxilio de la preposición $t a$, reforzada en ocasiones con el sustantivo man: t'así, t'allà, ta man d'así, ta man d'allà... Más precisiones sobre los usos catalanes y gascones en Corominas (1991: 114-115; DECat., s.v. est, ell, part).
} 
A veces cntra en combinación con astí para mostrar un punto (vago) más allá del indicado con el mero adverbio ${ }^{28}$ :

¿Agón l'has trobau ixo caixón? — ¡O!, astí dallà ‘đdónde has encontrado ese cajón? -por ahr' (Rm.).

\section{Referencias bibliográficas:}

Alarcos, E. (1994): Gramàtica de la lengua española, Madrid: Espasa Calpe.

Alvar, M. (con la colaboración de T. Buesa, A. Llorente y E. Alvar): Atlas Lingiuistico y Etnogràfico de Aragón, Navarra y Rioja, 12 vols., MadridZaragoza: C.S.I.C.-Inst. «Fernando el Católico», 1979-1983.

Alvar, M. (1953): El dialecto aragonés, Madrid: Gredos.

Alvar, M. (1954): «Dos cortes sincrónicos en el habla de Graus», AFA, 6, págs. 7 74.

Aivar, M. (1978): «Repertorio ansotano: encuestas de 1950», AFA, 22-23, págs. 21 48.

Alvar, M. - Pottier, B. (1987): Morfología histórica del español, Madrid: Gredos.

Arnal, M. L. (1998): El habla de la Baja Ribagorza occidental: aspectos fónicos y gramaticales), Zaragoza: Institución «Fernando el Católico».

Badía, A. (1950): El habla del valle de Bielsa (Pirineo aragonés), Barcelona: C.S.I.C.

Badía, A. (1981): Gramàtica històrica catalana, Barcelona: Tres i quatre, (cit. por la $3^{a}$ ed. de 1994).

Ballarín, A. (1972): Civilización Pirenaica, Zaragoza: La Editorial.

Ballarín, A. (1978): Diccionario del benasqués, Zaragoza: $2^{a}$ ed. aumentada y corregida.

Bayo, M. L. (1978): La comedia chesa "Qui bien fa nunca lo pierde» de D. Miral (estuclio lingiiístico), Zaragoza: I.F.C.

Castán, C. (1991): La descordada vida de Sinforosa Sastre (relato inédito).

Cooper, L. (1960): «On the Language of Upper Aragon (1258-1495)», HR, 28, págs. 262-275, cit. a través de la traducción de M. L. Arnal (1988) «Sobre la lengua del Alto Aragón (1258-1495)», AFA , 41, págs. 211-229.

Corominas, J. (1936): «El parlar de Cardós i Vall Ferrera», BDC, 23, págs. 241331 .

\footnotetext{
${ }^{2 *}$ Estructuras semejantes se reproducen en catalán, donde allà-dellà 'más allá de' (suroeste del catalán central, val.), cilli-dellà 'más lejos, más allá' (Ibiza), allà-deçà?, ací-deçà 'más acá de' (Mallorea) son usuales (DECat., s.v. ell).
} 
Corominas, J. (1991): El parlar de la Vall d'Aran (Gramàtica, diccionari i estudis lexicals sobre el gascó), Barcelona: Curial Edicions.

Corominas, J. (1980-1991): Diccionari etimològic $i$ complementari de la llengua catalana, 9 vols., Barcelona: Curial Ed.

Frago, J. A. (1977): «Varias calas documentales en el aragonés antiguo», AFA, 2021, págs. 323-326.

Frago, J. A. (1978): «Tres notas de diacronía lingüística: sobre fonética, morfología y sintaxis», AFA, 22-23, págs. 185-189.

Haensch, G. (1959): «Las hablas de la Alta Ribagorza», AFA, 10-11, págs. 57-193.

Haensch, G. (1974): «Las hablas del Valle de Isábena (Pirineo aragonés)», RDTP, 30, págs. 295-314.

Lapesa,, R. (1979): «Nominativo o caso oblicuo latinos como origen de demostrativos y artículo castellanos», en Höfler, Vernay, Wolf, I, págs. 196207.

Lloyd, P. M. (1993): Del latín al español. Fonología y morfología históricas de la lengua española (I), Madrid: Gredos (trad. de A. Álvarez del original inglés From Latin to Spanish. Vol. I: Historical phonology and morphology of the Spanish language, American Philosophical Society, 1987).

Menéndez Pidal, R. (1940): Manual de gramàtica española, Madrid: Espasa Calpe (cit. por la $20^{a}$ ed. de 1989).

Mott, B. (1989): El habla de Gistaín, Huesca: I.E.A.

Nagore, F. (1986): El aragonés de Panticosa. Gramàtica, Huesca, I.E.A.

Plaza Boya, A. (1990): «El dialecto del Valle de Benasque (comarca de Castejón de Sos). Bases para una morfosintaxis», Alazet, 2, págs. 155-236.

Rohlis, G. (1970): Le gascon. Études de philologie pyrénéenne, Tübingen: Max Niemeyer Verlag, $2^{\mathrm{a}}$ ed.

Saura, J. A. (1997): «La cuestión de la filiación filológica del benasqués actual desde una perspectiva fonético-fonológica», en Actas del I Encuentro "Villa de Benasque» sobre lenguas y culturas pirenaicas (Benasque, 1996), Zaragoza: DGA, págs. 307-334.

Saura, J. A. (1998): «Incrementos átonos benasqueses», Alazet, págs. 10, 159-179. Umphrey, G. W. (1911): «The aragonese dialect», RHi, 24, págs. 5-43, (cit. por trad. M. Alvar: «El dialecto aragonés»), AFA, 39, págs. 163-201. 